\title{
OS TRÓPICOS COMO LUGAR DAS SOMBRAS MATERIAIS E IMATERIAIS
}

Carlitos Luis Sitoie ${ }^{1}$

\section{Resumo}

Trópicos, corresponde as áreas geográficas delimitadas ao Norte e ao Sul pelo paralelo $23^{\circ}$, acontecendo o solstício de inverno e de verão, no instante em que o sol está sobre a linha imaginária do Trópico de Câncer e de Capricórnio respectivamente. Já quando o sol atinge a obliquidade sobre a linha imaginária do equador, acontece o equinócio das águas e das secas. Os solstícios e os equinócios são representados por meio da sobreposição de sombras físicas ou matérias de objetos e das coisas. O estudo analisou para além das sombras físicas, as sombras imateriais representadas por meio de ideias ou movimentos de reivindicação contra eurocentrismo, desencadeados pelos povos da África, Ásia e América. Os trópicos representam também a zona de temperatura, umidade, flora e fauna especifica, dinamizando atividades diversas com destaque ao safar, turismo de sol e praia, etc.

Palavras-chave: Trópicos, linha de equador, solstícios e equinócios.

\section{THE TROPICS AS THE PLACE OF MATERIAL AND IMMATERIAL SHADOWS}

\begin{abstract}
Tropics, corresponds to the geographic areas bounded to the North and South by the parallel $23^{\circ}$, with the winter and summer solstice occurring, at the moment when the sun is over the imaginary line of the Tropic of Cancer and Capricorn respectively. When the sun reaches the obliquity on the imaginary line of the equator, the equinox of water and drought occurs. Solstices and equinoxes are represented by superimposing physical or material shadows on objects and things. The study analyzed beyond the physical shadows, the immaterials represented through ideas or movements of claim against eurocentrism, triggered by the peoples of Africa, Asia and America. The tropics also represent the area of temperature, humidity, specific flora and fauna, promoting diverse activities, especially safar, sun and beach tourism, etc.
\end{abstract}

Keywords: Tropics, equator line, solstices and equinoxes.

\footnotetext{
${ }^{1}$ Doutorado em Ciências do Ambiente e Sustentabilidade na Amazônia pela Universidade Federal do Amazonas (2018). Mestrado em Educacao/Ensino de Geografia pela Universidade Pedagógica - Moçambique (2013).

Email: carlitossitoie@yahoo.com.br.
} 


\section{LOS TRÓPICOS COMO LUGAR DE LAS SOMBRAS MATERIALES E INMATERIALES}

\section{Resumen}

Trópico, corresponde a las áreas geográficas delimitadas al Norte y Sur por el paralelo $23^{\circ}$, ocurriendo el solsticio de invierno y verano, en el momento en que el sol se encuentra sobre la línea imaginaria del Trópico de Cáncer y Capricornio respectivamente. Cuando el sol alcanza la oblicuidad de la línea imaginaria del ecuador, se produce el equinoccio de agua y sequía. Los solsticios y equinoccios se representan superponiendo sombras físicas o materiales sobre objetos y cosas. El estudio analizó más allá de las sombras físicas, los inmateriales representados a través de ideas o movimientos de reivindicación contra el eurocentrismo, desencadenados por los pueblos de África, Asia y América. Los trópicos también representan el área de temperatura, humedad, flora y fauna específicas, promoviendo diversas actividades, especialmente safaris, turismo de sol y playa, etc.

Palabras clave: Trópicos, línea del ecuador, solsticios y equinoccios.

\section{INTRODUÇÃO}

Os trópicos são regiões onde habitam povos e biodiversidade que tolera as variações climáticas de temperaturas e precipitações altas, por vezes seca e outras úmidas, representando a trajetória máxima solar que estende-se desde $+23^{\circ}$ positivos no Câncer ao Norte até $-23^{\circ}$ negativos no Capricórnio ao Sul.

A visualização da linha imaginária do trópico de Câncer e Capricórnio pode ser feita por observação orientada de instrumentos astronómicos, de obeliscos e da sobreposição de sombras das coisas e objetos.

Dentre os estudiosos clássicos do assunto, aponta-se o Eratóstenes (cerca de séc. V a.n.e) como pioneiro a abordar os limites da trajetória solar, quando encontrou em papiros da biblioteca de Alexandria, uma informação anunciando que na cidade de Siene atual Assuã no Egito, ao meio dia ocorria solstício de verão, por volta de 21 de julho. O sol situava-se à $90^{\circ}$, iluminando as águas profundas do poço, sem ocasionar uma sombra, deduzindo a circularidade aparente solar.

A intensificação de debates sobre trópicos ganhou nova dinâmica quando estudos de astronomia conseguiram estabelecer de forma precisa, as coordenadas da eclíptica solar em $23^{\circ}$ sul e norte (N/S) simbolizando o "[...] movimento aparente solar de um solstício ao outro." (CONTI, 2010, p.49). Inspirando posições eurocêntricas, em alguns geógrafos como Emmanuel de Martonne, 1946 e Gourou, 1948, que defenderam o uso do termo apenas para áreas quentes 
e úmidas. Demangeot ([s. d.]), Planhol e Regnon(1970), estenderam o conceito para as áreas semiáridas, servindo de critérios para demarcar as regiões desérticas e mais tarde, os tristes trópicos do Claude Lévis-Strauss em 1955.

A importância dos trópicos, continuou motivando estudos, emergindo nos EUA e no Brasil, movimentos contrários à corrente eurocêntrica, em 1960 aparece a "[...] tropicologia de Gilberto Freyre e o tropicalismo de Edson Fonseca [...]" (FAVARETTO, 1996, p. 2). Movimentos que demonstravam que os trópicos úmidos não eram selvagens eram espaços geográficos com caraterísticas próprias fitogeográficas e povos com capacidades idênticas à daqueles que habitavam cidades e vilas europeias. As manifestações desse movimento eram feitas sob diversas formas, tais como: a arte, poesia, a lírica, música, etc., principalmente, nos grandes centros urbanos brasileiros da época como São Paulo, Rio de Janeiro, Recife em Pernambuco.

Partindo de Conti (2010), é possível afirmar que esse movimento, abriu espaço para nova abordagem acerca dos trópicos, que passaram a ser entendidos como categorias de análise, que agregam multiplicidade de variáveis ambientais. Como exemplo passaram a incluir aspectos culturais abordados na antropologia do "Tristes Trópicos" de Claude Lévis-Strauss, que incorporou os elementos históricos e geopolíticos. Assim como o sistema colonial que incorporou o conceito trópicos, para delinear projetos de produção agrícola direcionadas exclusivamente para as regiões das médias latitudes, produzindo culturas de rendimento como: algodão, chá, borracha, café, etc. Com esses estudos, os trópicos passam a ser entendido como faixa climática com fauna e flora própria, assim como, com povos diversos que vivem e fazem da região sua riqueza de exploração de recursos para a sobrevivência. Nessa perspectiva, o sistema colonial reconheceu as potencialidades da região para a produção de culturas de exportação no mercado internacional da época.

\section{LINHA DE CAPRICÓRNIO E CÂNCER}

Os conceitos atribuídos ao trópico de capricórnio e câncer são geograficamente utilizados como marco teórico para estabelecer limites de deslocação aparente solar na posição mais ao sul ou ao norte, limitando a incidência máxima dos raios solares na superfície terrestre, marcando transição de clima equatorial quente ao tropical no hemisfério sul ou ao norte. Já em astronomia os trópicos são definidos baseando-se nas linhas que separam as regiões da superfície de um planeta que, em virtude da rotação deste, cruzam em algum momento o plano 
orbital do planeta situadas mais ao norte ou mais ao sul que os trópicos, encontram-se sempre em um dos hemisférios definidos pelo plano orbital. Quer dizer, os trópicos do planeta coincidem com os círculos de latitude cujos valores são medidos a partir da linha imaginária do equador e igualam-se em módulo ao ângulo entre os planos orbital e equatorial do planeta. Para além dos trópicos, não há dia algum do ano no qual um objeto vertical deixe de produzir sombra. Na região tropical, objetos verticais não produzirão sombra em ao menos um dia do ano.

De acordo com Benchimol (1990), Silva (2006), Chermane Vieira (2011) e Varella (2013)é possível afirmar que Capricórnio e Câncer são linhas imaginárias demarcadas pela coordenada $23^{\circ} 26^{\prime} 22^{\prime \prime}$ de latitude sul e norte, essas coordenadas são variáveis dependendo de autor para autor. Para Silva (2004) a coordenada do capricórnio é $23^{\circ} 27^{\prime}$, Carvalho Junior et al. (2015), $23,4378^{\circ} \mathrm{Sul} 23^{\circ} 26^{\prime} 16^{\prime \prime}$, havendo outros que consideram situadas à $23^{\circ} 30^{\prime} ; 23^{\circ}$ 45', em diante, ocupando uma faixa de aproximadamente 911,3 Km e 102,188 Km de comprimento cada uma. A base para determinar o momento em que o sol atinge a posição de solstício é a partir da declinação solar $(\delta)$, que constitui o ângulo formado entre o Equador terrestre e a linha imaginária que contém o plano do sol. Os cálculos baseiam-se em diferentes fórmulas matemáticas, a saber: $\delta=23,45 *$ sen $[360(248+\mathrm{DJ}) / 365] ; \delta=23,45 *$ sen [(360/365).(DJ - 80)]] ou; $\delta=23,45 *$ sen [(2.( $\pi) / 365) .(284+D J)]] ;$ onde: $\delta$ é Declinação solar; a Multiplicação; Sen o Seno;DJ ao Dia Juliano e; П à decimal sexta letra do alfabeto grego Pi.

A linha de capricórnio e câncer agregam em sua dimensão teórica espaços geográficos com sete dimensões espaciais (latitude, longitude, altitude, temporalidades, sujeitos, objetos e coisas), dos trinta e dois países que atravessa, sendo Austrália, Madagascar, Namíbia, Zâmbia, África do sul, Moçambique, Brasil, Argentina, Chile e Paraguai no capricórnio, já Argélia, Nígeria, Líbia, Egito, Arábia Saudita, Emirados Árabes Unidos, Abu Dhabi (Omã), Índia, Bangladesh, Mianmar (Birmânia), China, Taiwan, Estados Unidos (Havai), México, Bahamas, Sahara ocidental, Mauritânia, Mali e Argélia cortados pelo trópico de câncer.

O território moçambicano é cortado pela linha do trópico de capricórnio que passa da província de Inhambane pelo distrito de Massinga no povoado de Haqui, Morrumbene, Funhalouro e atravessa a província de Gaza pelo distrito de Chigubo, Massingir e Mabalane até entrar na província do Limpopo na África do Sul. Nesse âmbito, o trópico de capricórnio, deixa de ser apenas uma linha imaginária, transformando-se em espaço geográfico tridimensionalmente socioambiental, por ser percebido, concebido e vivido (LEFEBVRE, 1974; 2006). Nesse caso, Capricórnio, simboliza, geossistemas que agregam redes, linhas, teias, ontogêneses, autopoiese, entre outras formas de referenciar a complexidade sistêmica, 
sendo constituídos esses lugares por variáveis ambientais representadas por meio do ar, solo, água e seres vivos, que formam uma totalidade denominada em geografia como geodiversidade.

A geodiversidade, permite aos moradores dos lugares atravessados pelas linhas dos trópicos, manter um modus vivendi próprios, que os diferencia e assemelha-os das vivências sociais de outros povos situados na mesma latitude. As diferenças surgem na luta pela sobrevivência, onde cada grupo social encontra maneiras diferenciadas para se adequar às condições fitogeográficas, proporcionadas pelo sistema ambiental especifico, numa região onde o sol perfaz a máxima declinação no momento do seu movimento aparente.

Sendo o sol a fonte primária que emite na superfície terrestre cerca de $(99,7 \%)$ de energia responsável pelos processos vitais, a sua distribuição depende da declinação ou posição dele, em relação a cada lugar do espaço geográfico, sendo que para Moçambique no povoado de Haqui, o sol encontra-se numa declinação de $-23,45$ sul, vide quadro (1).

\section{Quadro 1 - Posição solar no povoado de Haqui.}

\begin{tabular}{|c|c|c|c|}
\hline DIA DO MÊS & $\begin{array}{l}\text { NÚMERO DO } \\
\text { DIA DO ANO } \\
\text { (NDA) }\end{array}$ & $\begin{array}{l}\text { DECLINAÇÃO } \\
\text { SOLAR }(\delta)\end{array}$ & OBSERVAÇÃO \\
\hline 15 janeiro & 15 & $-21,27$ & \\
\hline 15 fevereiro & 46 & $-13,29$ & \\
\hline 15 Março & 74 & $-2,82$ & \\
\hline 21 Março & 80 & $\mathbf{0 , 0 0}$ & $\begin{array}{c}\text { Equinócio das águas em } \\
\text { Macapá }\end{array}$ \\
\hline 15 Abril & 105 & 9,41 & \\
\hline 15 Maio & 135 & 18,79 & \\
\hline 15 Junho & 166 & 23,31 & \\
\hline 21 Junho & 172 & 23,45 & Solstício de inverno \\
\hline 15 Julho & 196 & 21,52 & \\
\hline 15 Agosto & 227 & 13,78 & \\
\hline 15 Setembro & 258 & 2,22 & \\
\hline 20 Setembro & 263 & $\mathbf{0 , 0 0}$ & $\begin{array}{c}\text { Equinócio das secas em } \\
\text { Macapá }\end{array}$ \\
\hline 15 Otubro & 288 & $-9,60$ & \\
\hline 15 Novembro & 319 & $-19,15$ & \\
\hline 15 Dezembro & 349 & $-23,34$ & \\
\hline 20 Dezembro & 354 & $-23,45$ & $\begin{array}{c}\text { Festival das sombras em } \\
\text { Haqui } \\
\end{array}$ \\
\hline
\end{tabular}

Fonte: Elaborado por Carlitos Sitoie (2017)

A declinação foi obtida a partir de cálculos baseados na seguinte fórmula matemática: $\delta=23,45 * \operatorname{sen}[360(248+\mathrm{DJ}) / 365]$, sendo que, no dia (01) de Janeiro o sol encontra-se posicionado ao sul do equador com uma declinação de $(-23,01)=$ á $30(-17,78)$ e no dia 28 de 
fevereiro com uma declinação (-8,67); durante os dias (31) de março, (30) de abril, (31) de maio, (30) de junho, (31) de julho e (31) de agosto, o sol encontra-se no hemisfério Norte, com uma declinação magnética de $(+3,62),(+14,59), 31(+21,90),(23,18)$ e $(+18,17),+8,10)$, respectivamente. $\mathrm{O}$ solstício de verão no povoado de Haqui em Massinga acontece no dia 21 de Dezembro, no instante em que o sol atinge uma declinação magnética de $-23,45=$ à -27 ” $=$ $-0,45^{\circ}$

O NDA corresponde ao Número do Dia Juliano (DJ) que representa o dia do ano independente dos meses, isto é, representa a soma de dias, desde o primeiro de janeiro até a data que se pretende calcular a declinação solar, para o caso deste estudo, o dia do ano permite calcular a posição do sol em qualquer dia de ano em relação à Macapá e Haqui. Na cidade de Macapá quando a declinação é nula acontecem os equinócios das águas em março e das secas em setembro, enquanto que, no povoado de Haqui, quando o sol está na declinação máxima registra-se o solstício de verão em dezembro, conhecido pelos moradores como o momento das premissas de frutos de dezembro ou festival das sombras.

Enquanto cientificamente, a mobilidade aparente do sol é calculada a partir de fórmulas matemáticas, os moradores da cidade de Macapá e do povoado de Haqui em Massinga, usa seus saberes e práticas do dia a dia, que a partir da janela de seu apartamento ou habitação analisam e explicam as variações da movimentação aparente solar ao longo do ano.

Segundo Gundo Imbrie (1979) citado por Silva (2007), as descobertas matemáticas de Milankovitch explicam melhor a variação da intensidade dos efeitos da insolação com a latitude, referindo-se a influência do ciclo de obliquidade, a inclinação do eixo da Terra e o ciclo de precessão que provocam alterações na data, hora e dia dos equinócios e solstícios.

Em cada ciclo de quatro anos os equinócios tendem atrasar-se, quer dizer, ao longo do mesmo século tendem acontecer mais cedo, devido à órbita da terra que corre mais rápido quando está mais próximo do sol ou periélio do que quando está mais afastado ou afélio.

A radiação solar varia com a latitude ao longo de ano, sendo que para o povoado de Haqui, situado sobre a linha imaginária do Trópico de Capricórnio no paralelo de $23^{\circ} 26^{\prime} 22^{\prime \prime}$ latitude sul, vai receber maior quantidade de radiação solar em todo o ano, atingindo valores maiores no momento do solstício de verão, cerca de $\left(1250 \mathrm{~W} / \mathrm{m}^{2}\right)$, recebendo abaixo de $(800$ $\mathrm{W} / \mathrm{m}^{2}$ ) em cada unidade de tempo em um metro quarado durante o solstício de inverno. Essas variações fazem com que o povoado seja responsável pela diversidade socioambiental típica regional e com variações de biodiversidade capaz de suportar essas mudanças ao longo de ano, dinamizando estruturas organizacionais socioambientais. 
Organizar estruturas socioambientais significa que os animais e pessoas que habitam esta área geográfica do planeta Terra, organizam seu quotidiano em detrimento das variações térmicas estabelecendo fotoperíodo. Os animais, as plantas incluindo os seres humanos, apresentam uma homeostasia ou temperatura padrão, conhecida como fotoperiodismo em seres vegetais, exigindo adaptação a partir de estratégias reguladoras de temperaturas no organismo dos seres vivos. Nessa perspectiva, os moradores de Macapá usam ar-condicionado, banhos das praias, sombreamento, outras formas de ventilação e refrigeração de espaços ou ambiente vivido. Já no povoado de Haqui, usam o sombreamento de arborização, de palhotas, barracas e outros objetos que amenizam temperaturas altas.

Os animais e plantas que não respondem em espetro ótimo como, por exemplo, o camelão, a leseira baré, conhecida como preguiça baiana, caminham ou movimentam-se lento, o crocodilo entre outros animais hibernam para reduzir o metabolismo basal e permitir que o organismo continue funcionando. Cientificamente, o fotoperíodo pode ser calculado de forma a saber a capacidade que as plantas e animais podem suportar fora da situação de homeostasia. A formula matemática é:

$$
\mathrm{F}=\left\{2 / 15^{*} \operatorname{arc} \cdot \cos \left[\left(\operatorname{tg} \varphi^{*} \operatorname{tg} \delta\right)+1 / 60[43,7864+0,15150+0,01330]\right\}, \text { onde },+1 / 60[43,7864+0\right.
$$

$, 15150+0,01330]\}$ corresponde ao crepúsculo que é igual à $\pm 0,73$.

\section{LINHA DO EQUADOR E OS EQUINÓCIOS}

Para Júnior (2012), Araújo (2014), Trogello (20161), o Equador é uma linha imaginária da superfície terrestre em que a latitude astronômica é igual a $00^{\circ} 00^{\prime} 00^{\prime \prime}$ dividindo a terra em dois hemisférios “[...] geográficos norte e o hemisfério geográfico sul [...]” (MILONE, 2003, p.25). Com um raio de $6378 \mathrm{~km}$ correspondentes ao perímetro de $40075 \mathrm{~km}$. Atravessando teoricamente três oceanos (pacífico, atlântico e índico), quatro continentes (América, África, Ásia e Oceania), treze países (São Tomé, Gabão, República Democrática do Congo, Congo, Uganda, Quênia, Somália, Maldivas, Indonésia, Kiribati, Equador, Colômbia e Brasil).

No território brasileiro a linha do Equador atravessa o estado do Pará, Roraima (Rorainópolis), Amazonas (São Gabriel da Cachoeira) e o estado do Amapá cortando a cidade do Macapá. O Equador representa espaço geográfico constituído por territórios povoados por populações com culturas diferentes, apesar de compartilhar mesma latitude. Essas diferenças se notabilizam pelas formas diversificadas como esses povos exploram as potencialidades da situação geográfica, como é o caso da cidade de Macapá que organiza suas estruturas políticas 
e socioeconômicas aliando sua questão estratégica sob a linha imaginária do Equador, onde as variações das estações anuais são menos acentuadas.

Segundo Alves et al. (2009), o sol no seu movimento de translação da terra cruza a linha imaginária do Equador duas vezes por ano, fazendo com que o dia e a noite, tenham a mesma duração em todo o planeta. No instante em o sol está no zênite. Apesar dos equinócios acontecem apenas duas vezes por ano, a variação da radiação solar nos países atravessados pela linha do Equador não sofre variações ao longo do ano.

Na cidade de Macapá a intensidade de radiação solar é elevada ao longo de ano, atingindo valores extremos durante os equinócios das secas, em22 de setembro e das águas, em 21 de março.

A posição de Macapá permite que os raios solares percorram menor distância em relação ao plano de horizonte, fazendo que o lugar receba elevada quantidade de radiação solar, enquanto que o povoado de Haqui, por situar-se em latitude média, que é mais afastado do Equador, vai receber uma quantidade relativamente menor quando comparada com a de Macapá. Isto acontece porque à altura do Sol sobre o horizonte, reduz-se e os raios solares percorrem um trajeto mais longo na atmosfera antes de chegar a superfície do povoado.

\section{LEITURA E INTERPRETAÇÃO DE SOMBRAS DE MACAPÁ E HAQUI ATRAVÉS DE DIAGRAMAÇÃO SOLAR}

Partindo da ideia de que os solstícios e equinócios são visualizados pela sobreposição de sombras dos objetos que as projeta, é possível mapear sua mobilidade a partir de diagramas ou cartas solares que esquematizam as trajetórias ou itinerário do sol em datas referentes aos solstícios, equinócios ou datas intermediárias. Facilitando a análise e interpretação da insolação e da posição do sol em determinada data do ano em cada ponto da superfície terrestre, assim como, a projeção de sombreamento para diversos fins. A carta solar é uma representação gráfica ou esquemática demonstrativa do caminho que o sol e as sombras percorrem durante um dado tempo do dia, mês e ano.

Ribeiro (2003) explica que a diagramação solar depende da posição do observador correspondendo ao azimute e altura em relação ao sol, exigindo calibragem dos relógios solares em detrimento da coordenada geográfica, isto significa que, é importante a identificação do quadrante geográfico durante a diagramação. Se o diagrama for transportado mais para o norte ou para o sul as linhas do seu quadrante não correspondem mais as horas do dia do lugar, pois a insolação e o sombreamento alteraram suas trajetórias e características. 
Sabendo que a posição do sol em Macapá é diferente do povoado de Haqui, importa fazer análise de forma a comparar as experiências de uso e aproveitamento de sombras dos moradores das duas áreas geográficas de estudo, sendo assim, passamos apresentar o diagrama (GRÁFICO 1).

\section{Gráfico 1 - Mapa solar de Macapá}
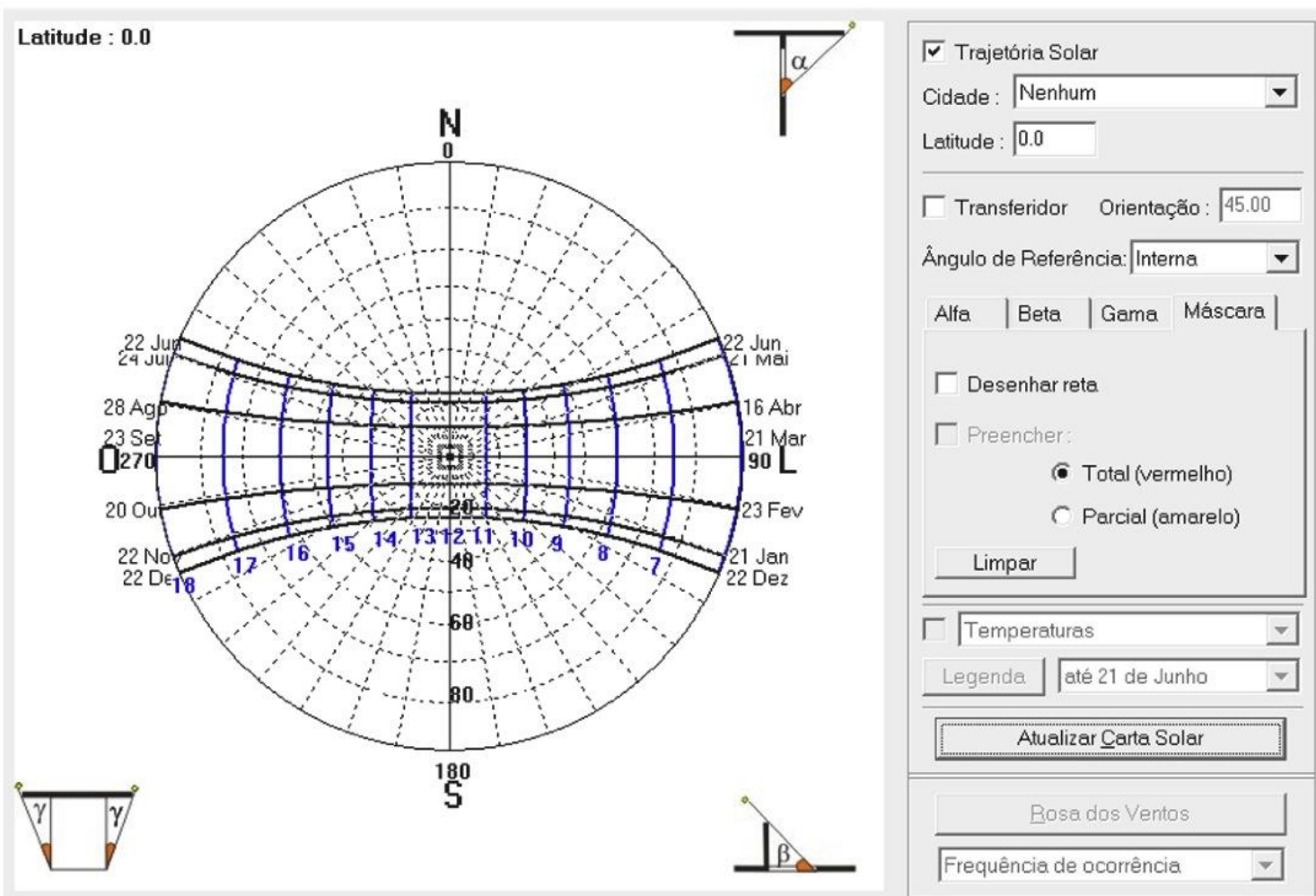

Fonte: Elaborado por Calitos Sitoie (2017), com recurso ao softwaresol-ar 6.2.

Com recurso ao softweresol-ar 6.2, foi possível representar uma projeção estereográfica da abóbada celeste, num plano horizontal simbolizando as diversas posições do sol e das sombras ao longo do ano na cidade de Macapá. As linhas curvas horizontais e verticais representam os meses e as horas do dia, respectivamente. As linhas horizontais indicam a projeção da trajetória solar durante os meses do ano, as horas do dia são representadas pelas linhas verticais (06h às 18h), apresentando os ângulos de azimute e a altura solar projetados em um plano.

Na carta solar de Macapá, estão congregadas três fontes de informação a saber: um anel externo com ângulos em relação ao norte $(\mathrm{N})$; a malha que facilita a localização das datas e horas; e um seguimento na parte inferior que fornece a inclinação dos raios (h), quer dizer, as linhas horizontais representam as datas do ano, já as verticais, os horários do dia para saber em 
que posição estará o sol e as sombras nessa data. Sendo que as sombras projetadas estão em um ângulo de noventa graus $\left(90^{\circ}\right)$ durante o meio dia local. Macapá, tem uma radiação solar a cima de treze horas diurnas e as sombras projetadas a oeste nas manhãs e para leste no final de dia, sempre sobrepostas cerca de meio dia local.

O cálculo do Ângulo Vertical de Sombra (AVS) projetada na cidade, pode ser feito tomando em conta que o sol está numa inclinação de noventa graus $\left(90^{\circ}\right)$, e usar a formula, AVS $=90$, AVS $=90^{\circ}-0^{\circ} ;$ AVS $=90^{\circ}$. Ou seja, o Ângulo Vertical de Sombra pela cidade de Macapá corresponde a uma inclinação de noventa graus $\left(90^{\circ}\right)$, quer dizer, as sombras são projetadas pelos objetos e coisas numa inclinação perpendicular correspondente a uma sobreposição ao longo do ano com pouca projeção para Leste nas manhãs e Oeste nas tardes.

Para o povoado de Haqui, que está situada nas latitudes médias vai apresentar outro comportamento em relação às sombras (GRÁFICO 2).

\section{Gráfico 2 - Mapa solar povoado de Haqui - Latitude, 23²6’22”.}

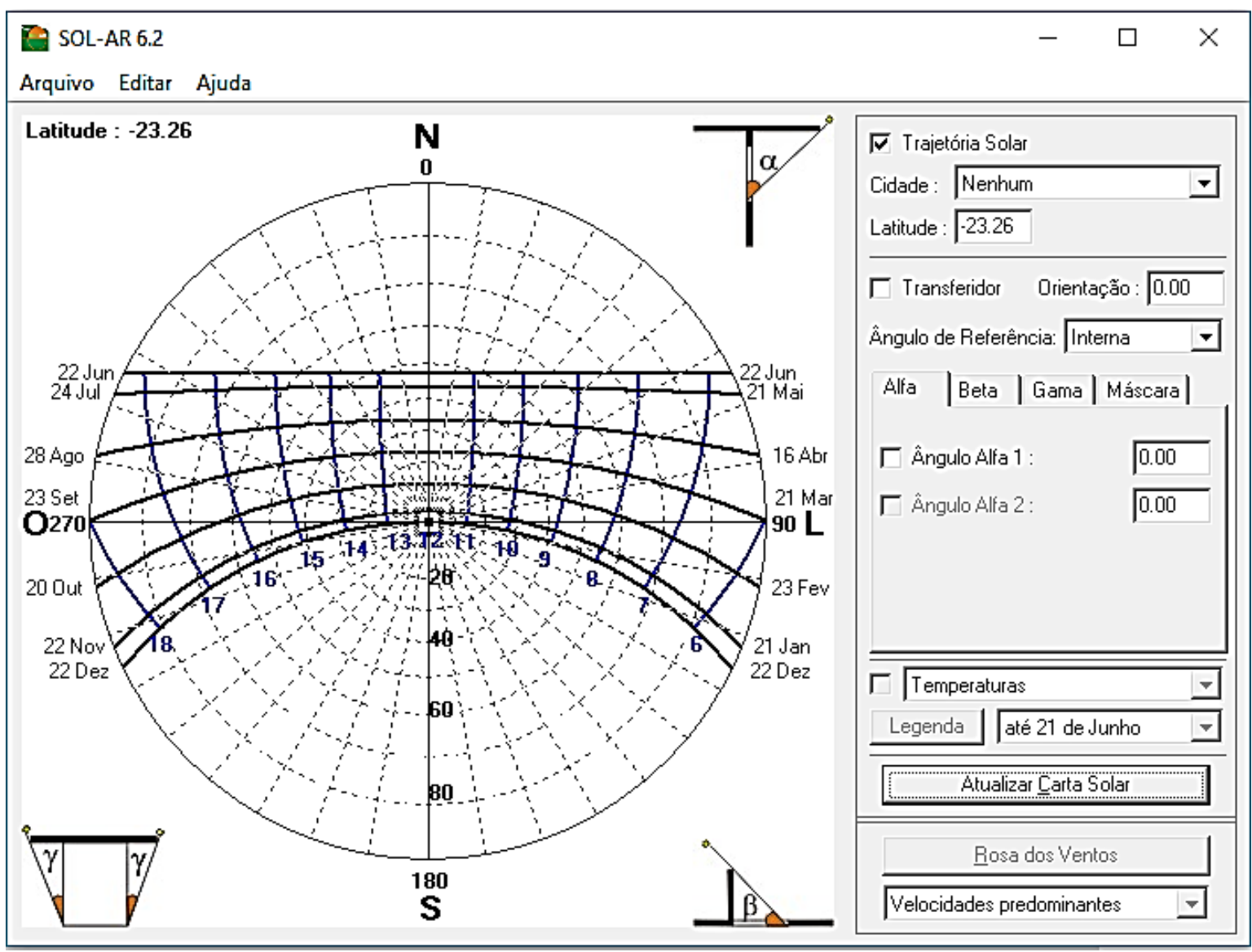

Fonte: Elaborado por Carlitos Sitoie (2017) com recurso ao Softweresol-ar 6.2. 
No diagrama solar está apresentado, os diferentes percursos ou pontos da passagem do sol e das sombras no povoado de Haqui ao longo do ano. As linhas horizontais estão em média de 30 dias representando os meses e as horas do dia, respectivamente. As linhas radiais indicam a azimute ou posição bussolar em relação ao norte magnético, já as circulares concêntricas indicam a altitude do sol desde o nascer até ao poente. Quer dizer, as linhas verticais que indicam as (5h30 às $18 \mathrm{~h} 30)$ indicam a posição em que estará o sol nessa data no povoado, permitindo prever a posição das sombras e a insolação. O ângulo de inclinação solar pode ser calculado usando a formula AVS $=90^{\circ}-23^{\circ} 26^{\prime \prime} 22^{\prime}$. O brilho solar ou insolação ultrapassa em média quatorze horas e as sombras são projetadas indicando três posições Leste, Noroeste e Sudeste. $\mathrm{O}$ sol tem uma inclinação que varia entre noventa $\left(90^{\circ}\right)$ graus à vinte e três $\left(23^{\circ}\right)$ graus.

\section{CONSIDERAÇÕES FINAIS}

Os trópicos e equador são linhas imaginárias que atravessam paralelamente o globo terrestre, delimitando as principais regiões climáticas da superfície terrestre, acontecendo os solstícios e equinócios respectivamente. Os trópicos de capricórnio e câncer atravessam trinta e dois países, já o equador treze, influenciando vivências dos povos que habitam lugares atravessados por essas linhas imaginárias.

O estudo procurou analisar a importância da categoria trópico, sendo usada ao longo da história para designar ideias referentes ao movimento de reivindicação ao eurocentrismo, como aconteceu no Brasil com o tropicalismo e a tropicália, assim como para delimitar a área geográfica referente a faixa entre o trópico de câncer e capricórnio passando pela linha do equador com suas características fitogeográficas.

A posição e ângulo de inclinação solar são responsáveis pelas dinâmicas ambientais que influem nas variações termo pluviométricas, na distribuição da fauna e da flora, assim como no comportamento dos seres vivos em consonância com o fotoperiodismo, abscisão foliar e homeostasia.

\section{REFERÊNCIAS}

AFONSO, G. Mitos e estações no céu tupi-guarani. Scientific American Brasil, n. 45, p. 3847, 2006.

ALVES, S. A matemática do GPS. Revista do Professor de Matemática, RPM, n. 59, 2006. Disponível em: 
<http://www.sinaldetransito.com.br/artigos/GPS_para_engenharia_\%20de_\%20transito.pdf >. Acesso em: 19 fev. 2016.

ALVES, Sérgio; CARVALHO, João Pitombeira; MILIES, Francisco César Polcino. A geometria do globo terrestre. [S.1.]: IME/USP, 2009. Disponível em: <http://www.bienasbm.ufba.br/M29.pdf >. Acesso em: 20 fev. 2016.

ARAÚJO, Diones Charles Costa de. Uma proposta para a inserção de topicos de astronomia indigena Brasileira no ensino médio: desafios e possibilidades. 2014. 185f. Dissertação. (Mestrado em Ensino de Ciência) - Universidade de Brasília DF, Brasília, 2014.

AXT, Rolando; SILVEIRA, Fernando Lang da. Um intrigante fenômeno óptico: atração entre as sombras. Física na escola. v. 8, n.1, 2007.

BENCHIMOL, Samuel, et. al. Trópico e Meio ambiente. Trópico Geo-Bio-Social: Anais do seminário de tropicologia. Fundação Joaquim Nambuco, Recife: FJN, Editora Massangana, 2002.

CARVALHO JUNIOR, Waldir de; FILHO. Braz Calderano; CHAGA. Cesar da Silva; BHERING. Silvio Barge; Nilson Rendeiro PEREIRA. Os solos tropicais: uma visão segundo bases mundiais de livre acesso. In: Simpósio Brasileiro de Sensoriamento Remoto - SBSR, 17. João Pessoa-PB, 25 a 29 de abril de 2015. Anais... João Pessoa: INPE, 2015. Disponivel em: <https://www.alice.cnptia.embrapa.br/bitstream/doc/1019666/1/2015015.pdf.> Acesso em: 28 de dez. 2017.

CHERMAN, Alexandre; VIEIRA, Fernando. O tempo que o tempo tem: Por que o ano tem 12 meses e outras curiosidades e outras curiosidades sobre o calendario. 2. ed. Rio de Janeiro: ZAHAR, 2011.

CONTI, Bueno José. Geografia e tropicalidade.Revista da Casa da Geografia de Sobral,v. 12, n.1, p.47-58, 2010.

FAVARETTO, Celso F. Tropicália: alegoria, alegria. Cotia/SP: Ateliê editorial, 1996. MILONE, André de Castro. Astronomia no dia a dia. São José dos Campos: INPE, 2003.

RIBEIRO, C. A. M. Aplicação de técnicas de geoprocessamento para análises das relações entre o fator de visão do céu e as diferentes orientações da malha urbana . Monografia (Superior de Tecnologia Em Geoprocessamento ) - Instituto Federal de Educação, Ciência e Tecnológica da Paraíba, João Pessoa, 2003.

RODRIGUES JUNIOR, Manoel Alves. Os calendários e sua contribuição para o ensino da astronomia. 2012. Dissertação (Mestrado em Física e Astronomia) - Universidade do Porto Departamento de Física e Astronomia, Porto, 2012.

SILVA, J.G.R. Ciclos orbitais ou ciclos de Milankovitch. Textos de GlossárioGeológico Ilustrado, 2007.

SILVA, Mário Adelmo Varejão. Meteorologia e climatologia. Versão digital, Recife, v. 2, mar. 2006. 
SILVA. Roberto G. Predição da configuração de sombras de árvores em pastagens para bovinos.I Simpósio sobre Sombreamento na Bovinocultura Tropical, Jaboticabal - SP, 2004. Disponível em: https://repositorio.unesp.br/bitstream/handle/11449/27779/S010069162006000100029.pdf?sequence=1\&isAllowed=y. acesso em: 28 de dez. 2017.

TROGELLO, Anderson Giovani. Objetos de aprendizagem: uma sequência didática para o ensino de astronomia, 2015. Acesso em: 8 jan. 2016.

VARELLA, Irineu Gomes. O sol fica apino na sua cidade. CoelumAustrale. Jornal pessoal de astronomia, física e matemática, ano 4, n. 29, fev 2013.

Recebido em Junho de 2020

Aprovado em Julho de 2020

Publicado em Fevereiro de 2021 